\section{Commentary: Chasing solutions versus chasing windmills}

\author{
Anthony W. Kim, MD, and Elizabeth A. David, MD
}

The idea that cardiothoracic surgeons are part of a larger group of clinicians deemed to be "commodity physicians" is entirely misguided. Yet, there are some individuals in the business of medicine who actually believe that cardiothoracic surgeons are just as replaceable or interchangeable as any other organizational entity. This sentiment is simply untrue and one that fosters a mindset that institutional loyalty is unnecessary. In reality, cardiothoracic surgeons are the ones who routinely demonstrate a never-ending commitment to their patients, colleagues, and, yes, even to their institutions. Being rewarded for this type of loyalty and degree of effort by nonphysician executives is rare. Therefore, seeking validation in this regard from the healthcare executive is a Cervantes-esque exercise in chasing windmills.

In exposing the impact of staff turnover during cardiac surgery, Bloom and colleagues ${ }^{1}$ highlight that the battles for which cardiothoracic surgeons fight, including first case starts and limiting personnel turnovers, are not whimsical crusades. These issues may be perceived as ones that pertain to surgeon convenience, but to the contrary, these interests are of paramount importance because they are associated with genuine downstream consequences such as mortality. The fact that a venerated cardiothoracic surgery team is raising awareness in a domain that traditionally has belonged to the hospital administrator in charge of operational matters highlights the benefits of surgeons translating the impact of nonclinical decisions on delivering clinical care. Presently, there are many executives who believe they know what busy cardiothoracic surgeons are experiencing, but in truth, they have no idea as to what actually transpires

\footnotetext{
From the Division of Thoracic Surgery, Keck School of Medicine, University of Southern California, Los Angeles, Calif.

Disclosures: Authors have nothing to disclose with regard to commercial support.

Received for publication Dec 17, 2019; revisions received Dec 17, 2019; accepted for publication Dec 18, 2019; available ahead of print Jan 8, 2020.

Address for reprints: Anthony W. Kim, MD, Division of Thoracic Surgery, Keck School of Medicine, University of Southern California, 1510 San Pablo St, Suite

514, Los Angeles, CA 90033 (E-mail: anthony.kim@med.usc.edu).

J Thorac Cardiovasc Surg 2021;161:145-6 0022-5223/ $\$ 36.00$

Copyright (c) 2020 Published by Elsevier Inc. on behalf of The American Association for Thoracic Surgery

https://doi.org/10.1016/j.jtcvs.2019.12.066
}

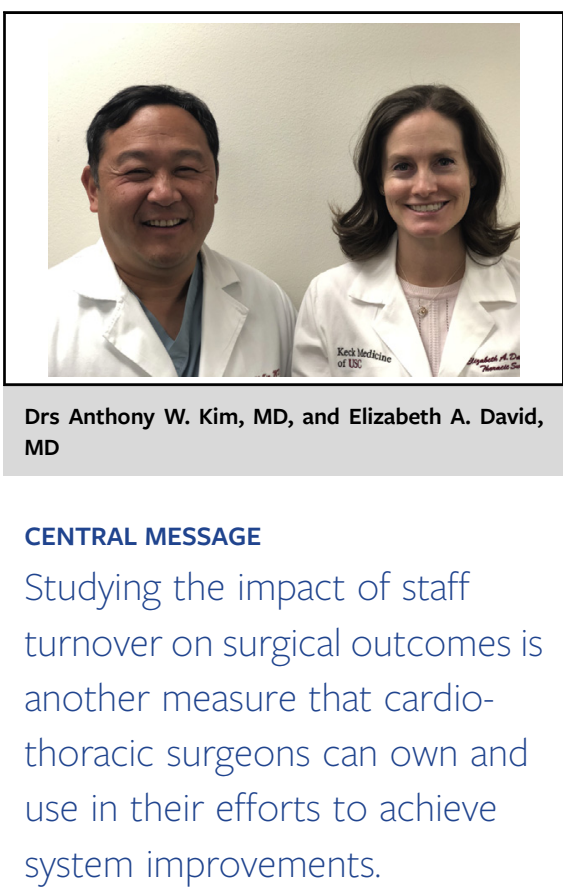

on a daily basis. The idea that there even is an impact of staff turnover on patient outcomes most likely resides at a more remote level of concern behind other fiscal matters. Understanding this reality may be completely foreign to someone who is not present in the operating room as much as a cardiothoracic surgeon. The executive translation of the impact of staff turnover possibly would be to ask an executive to work with a new administrative team every day. Errors of omission and commission would occur that would test even the most patient of executives, but assuredly, these would be addressed with priority. The importance of studying operational problems such as staff turnover and other issues identified by Bloom and colleagues ${ }^{1}$ is that it conveys the powerful message that addressing these problems must be a priority as it actually translates into doing right by the patient. This core tenet is an immutable underpinning that can never be relegated to anything less than the most important priority of a healthcare system and its leaders. In this regard, the authors ought to be lauded for actually chasing solutions.

In the wonderful article entitled "Simone's Maxims,", a retiring academic surgeon noted in his second maxim that "institutions don't love you back." Striving for reciprocity when it comes to loyalty for cardiothoracic surgeon effort is a Quixotic mission. Instead, our cardiothoracic surgeon-leaders have demonstrated that a more practical, 
realistic, and effective means to drive change is to investigate and own the data in the operational or administrative domain in addition to the clinical or surgical realms. In doing so, we continue to be the nobles of our profession and prove that we are not squires of a system.

\section{References}

1. Bloom JP, Moonsamy P, Gartland RM, O'Malley C, Tolis G, VillavicencioTheoduloz MA, et al. Impact of staff turnover during cardiac surgical procedures. J Thorac Cardiovasc Surg. 2021;161:139-44.

2. Simone JV. Understanding academic medical centers: Simone's maxims. Clin Cancer Res. 1999;5:2281-5.
See Article page 139.

\section{Commentary: Performance, safety monitoring, and needle counts in the operating room}

\author{
John M. Karamichalis, MD, FACS
}

Cardiac surgery operations have a low error tolerance and share many unique properties with high technology systems and military operations in which performance and outcomes depend on complex individual, technical, and organizational factors and their interactions. ${ }^{1}$ In those systems often referred to as "complex socio-technical systems," human factors research has been a major contributor to risk management and reliability enhancement.

Although patient outcomes in cardiac surgery are multifactorial, the patient's intraoperative course is of paramount importance. ${ }^{2}$ The surgical community is placing an intense focus on the microcosmos and team interactions in the operating room in an attempt to analyze all possible outcome associations.

Safety monitoring in the operating room and the concept of "near miss" were explored 20 years ago to detect warnings of suboptimal performance in the arterial switch operation in a multicenter study by analyzing minor and major events representing various types of human errors. ${ }^{1}$ Both minor events (eg, instrument handling errors by the scrub nurse, communication or coordination errors) and major events (eg, technical errors) had a strong correlation

From the Cardiac Surgery, LeBonheur Children's Hospital and University of Tennessee Health Science Center, Memphis, Tenn.

Disclosures: Author has nothing to disclose with regard to commercial support.

Received for publication Jan 1, 2020; revisions received Jan 1, 2020; accepted for publication Jan 2, 2020; available ahead of print Jan 22, 2020.

Address for reprints: John M. Karamichalis, MD, FACS, LeBonheur Children's Hospital, University of Tennessee Health Science Center, 49 Dunlap St, Level 3, Memphis, TN 38104 (E-mail: jkaramichalis@yahoo.com).

J Thorac Cardiovasc Surg 2021;161:146-7

$0022-5223 / \$ 36.00$

Copyright (c) 2020 by The American Association for Thoracic Surgery

https://doi.org/10.1016/j.jtcvs.2020.01.008
Check for updates

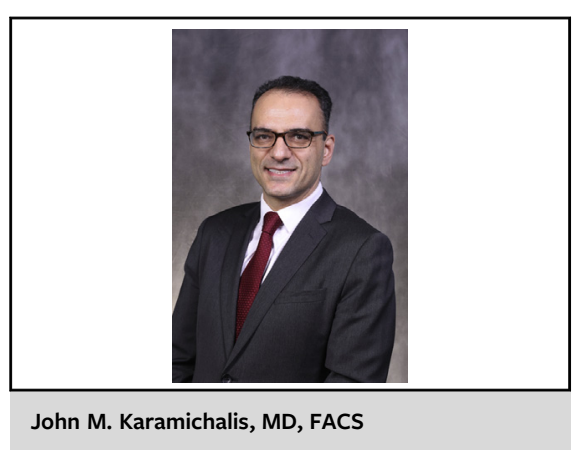

CENTRAL MESSAGE

Safety monitoring in the

operating room is of paramount

importance for cardiac surgery

performance improvement.

SCEs are associated with high

staff turnover and are likely

surrogates of suboptimal team

member dynamics.

with patient outcomes (mortality or near-miss). It is no surprise that the present study by Bloom and colleagues ${ }^{3}$ elicits a significant association of sharp count error (SCE) with mortality. More important, this study exposed the impact of increased team turnover, such as nursing and scrub personnel, on care in the operating room with a significant association with SCEs. The sophisticated organizational structure and function of the cardiac operating rooms require the coordinated efforts of multiple people working together as a team with high levels of cognitive and technical performance of precise tasks.

The impact of staff turnover on SCEs and its possible association with patient outcomes as examined by Bloom and colleagues ${ }^{3}$ in this article are important contributions in delineating yet again the delicate interaction of operating room team dynamics and patient outcomes. Although SCEs were associated with high staff turnover and mortality, this 